\title{
ADVANCES IN EPR DOSIMETRY IN TERMS OF RETROSPECTIVE DETERMINATION OF ABSORBED DOSE IN RADIATION ACCIDENTS
}

\author{
TOMASZ KUBIAK
}

Poznan Science and Technology Park of Adam Mickiewicz University Foundation, Poznań, Poland

Received January 01, 2018; accepted May 17, 2018; published online May 28, 2018

\begin{abstract}
The electron paramagnetic resonance measurements of dosimetric signals originating from radicals generated under the influence of ionizing radiation allow to determine the dose absorbed by the casualties of radiation accidents. The study material can consist of victim's teeth, bones or nails. Also human hair and mineral glass from personal electronic devices, that people had in the moment of accident, are considered to be useful in dosimetry. Although X-band $(9.4 \mathrm{GHz})$ spectrometers predominate, Q-band devices (34 GHz) enable to increase the sensitivity of measurements and reduce the size of specimens, whereas L-band machines (1.1 GHz) are suitable for in vivo dosimetry. The EPR tooth enamel dosimetry has been used many times to assess the cumulative radiation dose and health risk in people living in areas contaminated due to the radiation accidents and to determine the unknown absorbed doses in patients after the overexposures during radiotherapy treatment.
\end{abstract}

\section{INTRODUCTION}

Electron paramagnetic resonance (EPR, also called electron spin resonance, ESR) dosimetry is recognized as the fundamental method of retrospective dose assessment after radiological accidents. The measurements base on radiation-induced radicals, which are generated under the influence of ionizing radiation in biological materials: tooth enamel, bones, finger- and toenails (Trompier, Romanyukha, Reyes, Vezin, Queinnec \& Gourier, 2014a). Moreover, an option of using such fortuitous materials as mineral glass from watches and displays of personal electronic devices is considered (Trompier, Della Monaca, Fattibene \& Clairand, 2011).

Research on paramagnetic centers generated by ionizing radiation in various materials has a long history. In the 1950s intensive EPR studies were devoted to so-called F- centers (name from the German word "Farbzentrum") produced in crystals (Kip, Kittel Levy \& Portis, 1953). In the course of time more biologically oriented works have appeared. It is worth mentioning the EPR investigation of X-ray irradiated keratin in the early 1960s (Rajewsky \& Redhardt, 1962). The first comprehensive study of the suitability of various tissues as a dosimetric material proved that unlike soft tissues, human bones, teeth and fingernails can be used for the assessment of absorbed dose using EPR method (Brady, Aarestad \& Swartz, 1968). Since that time a rapid development of EPR dosimetry has been observed.
EPR spectroscopy informs about the interaction between microwave electromagnetic radiation and a sample with unpaired electrons, which is placed in an external magnetic field. Although X-band $(9.4 \mathrm{GHz})$ spectrometers predominate, systems operating at the higher frequency of $34 \mathrm{GHz}$ (Q-band) or lower of 1.1 $\mathrm{GHz}$ (L-band) are increasingly used. The resonant absorption of microwave energy by radiation-induced radicals in the specimen is translated into the absorbed dose (Williams, Flood, Salikhov, Kobayashi, Dong, Rychert, Du, Schreiber \& Swartz, 2014).

Different paramagnetic centers, present in the sample collected from victim, are recognized by characteristic $g$-factor value. The measured intensity of radiationinduced signal (RIS) enables to determine the absorbed dose, that can be done using either the additive dose or the calibration curve method. In the popular additive dose method after the measurement of initial dosimetric signal the sample is gradually irradiated with known doses. Each time the increasing peak-to-peak amplitude of RIS is recorded to determine the linear relation between the signal intensity and artificially added dose (Trompier, Sadlo, Michalik, Stachowicz, Mazal, Clairand, Rostkowska, Bulski, Kulakowski, Sluszniak, Gozdz \& Wojcik, 2007a). EPR standard sample, e.g. $\mathrm{Mn}^{2+} / \mathrm{MgO}$, is used to normalize the spectrometer response and ensure the reproducibility of measurements (Gualtieri, Colacicchi, Sgattoni \& Giannoni, 2001; Wilcox, He, Gui, Ruuge, Li, Williams \& Swartz, 2010). In order to determine the dose correctly it is important to check whether the quality factor of the cavity remains 
constant during the entire series of measurements. The permanent presence of an appropriate reference sample in the cavity facilitates the compensation of Q-factor variations (Sleptchonok, Nagy \& Desrosiers, 2000). Retrospective assessment of the initial dose is done by extrapolation to zero ordinate by the method of least squares (Gualtieri et al., 2001). In patients treated with radiation before the accident the dose given during the previous treatment has to be subtracted. Lifetime dose from natural background radiation also must be taken into consideration in case of cumulative dosimeters such as tooth enamel (Zhumadilov, Ivannikov, Stepanenko, Zharlyganova, Toyoda, Zhumadilov \& Hoshi, 2013).

The second way to determine the dose is the calibration curve method, in which equal samples (e.g. taken from a pool of enamel or mineral glass) are irradiated to various known doses with a calibrated radiation source. It is important to use only the doses higher than the detection limit (Fattibene, Trompier, Wieser, Brai, Ciesielski, De Angelis, Della Monaca, Garcia, Gustafsson, Hole, Juniewicz, Krefft, Longo, Leveque, Lund, Marrale, Michalec, Mierzwińska, Rao, Romanyukha \& Tuner, 2014). The EPR intensities of RIS are plotted as a function of doses received by the successive calibration specimens. The best linear fit creates the calibration curve. The x-axis intercept of the graph represents the average initial dose (e.g. from background radiation) of the calibration samples and intrinsic uncertainties related to the measurements and spectra processing (Volchkova, Shishkina, Ivanov, Timofeev, Fattibene, Della Monaca, Wieser \& Degteva, 2011).

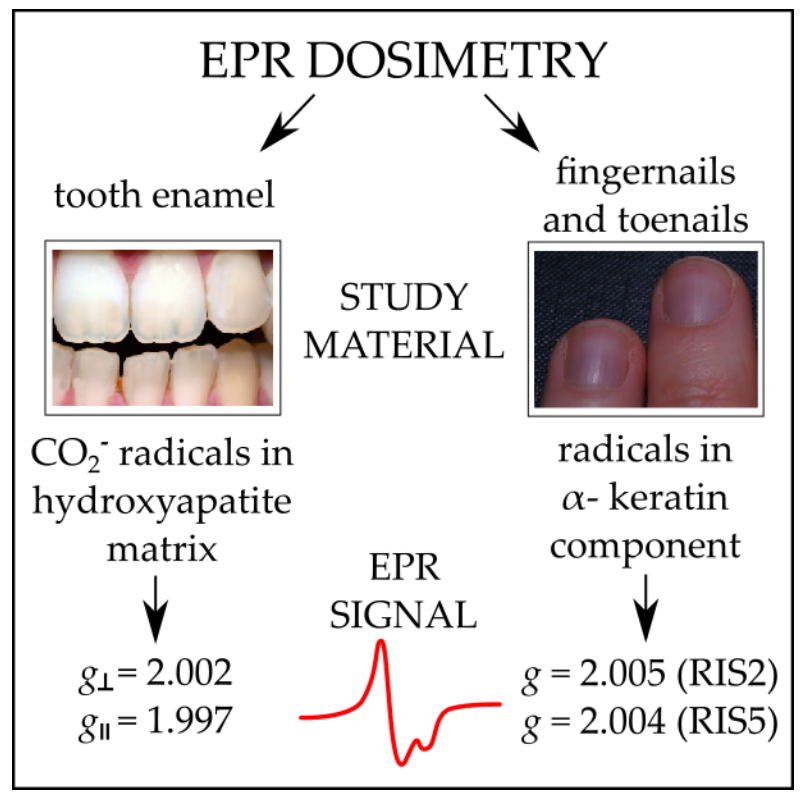

Fig.1. EPR dosimetry bases on the measurements of radiationinduced signals (RIS) that originate from radicals generated under the influence of ionizing radiation.
After the precise determination of the amplitude of the EPR signal of the sample from a patient exposed to unknown dose, one can compare its radiation response with the calibration curve. Particular attention should be paid during the analysis of signals from irradiated protective glasses, because significant variability both in the shapes and the intensities of EPR spectra has been observed depending on the brand of smartphone (Sholom \& McKeever, 2017). In general, the prospective use of fortuitous materials in EPR dosimetry still requires many tests, therefore biological samples are mainly utilized. Fig. 1. summarizes the most important information about EPR biodosimetry.

\section{TOOTH ENAMEL EPR DOSIMETRY}

The EPR studies of radiation-induced signals in tooth enamel samples are fundamental for the reconstruction of absorbed dose in the situation of radiation accidents. Teeth are lifelong cumulative individual dosimeters (Gualtieri et al., 2001), because the carbonate radical centers formed in the enamel under the influence of ionizing radiation are extremely stable and can exist at room temperature even $10^{7}$ years (Romanyukha, Mitchell, Schauer, Romanyukha \& Swartz, 2007; ElFaramawy, 2005). Although initially some scientists attributed the RIS to $\mathrm{CO}_{3}{ }^{3-}$ radicals, nowadays researchers are unanimous that $\mathrm{CO}_{2}^{-}$radicals are responsible for this signal (Gualtieri et al., 2001; ElFaramawy, 2005; Wieser, Vasilenko, Aladova, Fattibene, Semiochkina \& Smetanin, 2014). Carbon dioxide paramagnetic centers are generated by the radiation based on carbonate ions, which are incorporated into the hydroxyapatite $\left[\mathrm{Ca}_{10}\left(\mathrm{PO}_{4}\right)_{6}(\mathrm{OH})_{2}\right]$ crystal matrix of teeth during the mineralization process (Wieser et al., 2014; Bhat, 2005). The tooth enamel is easily affected by photon (X-rays and gamma rays) and beta radiation (Williams et al., 2014; Fattibene \& Callens, 2010). On the other hand, the sensitivity to neutrons originating from a reactor is weak and the experiments performed with a mixed neutron - gamma field have shown that it is impossible to distinguish between photon and neutron dose components using only the EPR signal of tooth enamel (Trompier, Fattibene, Tikunov, Bartolotta, Carosi \& Doca, 2004; Trompier, Tikunov, Ivannikov \& Clairand, 2006). Also the response of enamel to high LET radiation is definitely lower than for $\mathrm{X}$ or gamma rays, which was demonstrated by EPR measurements of teeth irradiated with carbon ions from medical accelerator (Yamaguchi, Sato, Kawamura, Hamano, Yoshii, Suda, Miyake, Kunugita, 2016).

Dental enamel EPR dosimetry can be used not only in case of overexposures of patients in medical treatment centers but also after large-scale accidents in nuclear 
facilities. It is worth noting that the EPR radiationinduced signal is unaffected by dose rate (Williams et al., 2014) and independent of the tooth position in mouth (El-Faramawy, 2005). In spite of many advantages, conventional X-band EPR dosimetry has got one main drawback. The precise measurements of doses below $500 \mathrm{mGy}$ are possible only with the large (100 mg) purified enamel samples (Romanyukha, Trompier \& Reyes, 2014a), so there is a need for using of extracted or exfoliated teeth (Trompier, Romanyukha, Kornak, Calas, LeBlanc, Mitchell, Swartz \& Clairand, 2009). Even though the milk teeth of children can be relatively easily collected in case of emergency, there is a problem with permanent teeth. Restorations and large carious lesions debar them from EPR studies (Pass, De, Romanyukha \& Misra, 2009). Moreover, only molars are used to minimize the influence of sunlight on tooth enamel (Gualtieri et al., 2001), because UV component also generates radicals and thus skews the dose measurement (Fattibene \& Callens, 2010). This is the reason why incisors and canines are usually excluded from dosimetric measurement (Bhat, 2005) and the number of radicals observed in teeth situated in the lower jaw is greater compared with the upper jaw (ElFaramawy, 2005). Additionally, the preparation of enamel specimens is time-consuming (Romanyukha et al., 2014a). The enamel sample must be precisely separated from dentine, which gives lower EPR signal (Gualtieri et al., 2001). It can be done mechanically using dental drills and diamond saws (Zhumadilov, Ivannikov, Zharlyganova, Zhumadilov, Stepanenko, Abralina, Sadvokasova, Zhumadilova, Toyoda, Endo, Okamoto \& Hoshi, 2011). The use of saws and drills without water cooling causes the increase in temperature of the sample due to the friction and thus generates radicals responsible for narrow mechanically induced EPR signal with $g$-value of 2.0032 and linewidth of about 0.1 mT (Aragno, Fattibene \& Onori, 2001). However, it is possible to eliminate unwanted signals from the external layers of the specimen by chemical treatment of the sample with orthophosphoric acid. Acid etching not only removes the residual dentin and mechanically induced radicals but also reduces the native bulk background EPR signal (Onori, Aragno, Fattibene, Petetti \& Pressello, 2000). Before measurements tooth enamel is crushed with surgical pliers or in a mortar to a powder. The size of the grains is usually in the range from $125 \mu \mathrm{m}$ to $1.5 \mathrm{~mm}$ (Zhumadilov et al., 2013; El-Faramawy, 2005; Zhumadilov et al., 2011). In case of larger granular samples their position in the EPR cavity should be checked using a goniometer in order to find the maximal intensity of RIS and avoid the effect of anisotropy (Chumak, Sholom, Bakhanova, Pasalskaya \& Musijachenko, 2005). This maximal amplitude is observed when the main magnetic field of spectrometer
$\left(B_{0}\right)$ is perpendicular to the enamel chip surface and parallel to the long axis of the hydroxyapatite microcrystals (Gualtieri et al., 2001). The angle dependent radiation-induced signal has $g_{\perp}=2.0019$ 2.0025 and $g_{\|}=1.9973$ (Romanyukha et al., 2007; ElFaramawy, 2005).

Aside from the dosimetric signal the X-band EPR spectrum of irradiated tooth enamel includes also the native background signal with $g=2.0045$. It has asymmetric shape, with a peak-to-peak line width $\left(\Delta B_{p p}\right)$ of $0.8 \mathrm{mT}$ and probably originates from the organic content of enamel (El-Faramawy, 2005). Dependence of the native signal intensity on grain size has been observed (Sholom, Haskell, Hayes, Chumak \& Kenner 1998). Due to the fact that the background signal, which is not affected by radiation, is situated close to the dosimetric signal, the intensity of the high-field line of RIS $(g=1.9973)$ is measured to minimize the overlapping effect and accurately assess the absorbed dose (Gualtieri et al., 2001). In case of deciduous teeth the unwanted background signal is slightly shifted to the higher field (smaller $g$ factor) compared with permanent teeth. Both types of teeth exhibit similar sensitivity to gamma radiation, but larger variation in dosimetric signal intensities for milk teeth may result in greater uncertainty during the dose estimation by means of calibration curve method (Murahashi, Toyoda , Hoshi, Ohtaki, Endo, Tanaka, Yamada, 2017).

Although the mean value of the dose detection limit for X-band tooth enamel measurements was found to be $193 \pm 91 \mathrm{mGy}$, it can be lowered to $29 \mathrm{mGy}$ using a special measurements procedure and an advanced EPR spectrometer (Romanyukha et al., 2014a; Fattibene, Wieser, Adolfsson, Benevides, Brai, Callens, Chumak, Ciesielski, Della Monaca, Emerich, Gustafsson, Hirai, Hoshi, Israelsson, Ivannikov, Ivanov, Kaminska, Ke, Lund, Marrale, Martens, Miyazawa, Nakamura, Panzer, Pivovarov, Reyes, Rodzi, Romanyukha, Rukhin, Sholom, Skvortsov, Stepanenko, Tarpan, Thierens, Toyoda, Trompier, Verdi \& Zhumadilov, 2011).

\section{EPR BONE DOSIMETRY}

Bone samples, which are collected from patients undergoing surgical procedures, can also constitute material for EPR dosimetry. Such specimens are frequently used to determine the dose absorbed by the casualties of accidents related to failures of the equipment for radiotherapy or nuclear medicine diagnostics (Trompier et al., 2007a; Clairand, Huet, Trompier \& Bottollier-Depois, 2008). The radiationinduced signal derives from long-lived $\mathrm{CO}_{2}{ }^{-}$radicals generated as a result of the ionization of carbonate impurities in hydroxyapatite matrix. Bones contain the lover amount of hydroxyapatite (50-60\%) in comparison 
with tooth enamel (96\%) (De, Romanyukha, Trompier, Pass, Misra, 2013). Furthermore, the EPR measurements are more difficult due to the stronger background signal associated with the higher content of organic components (collagen and protein polysaccharides) (De et al., 2013; Ciesielski, Krefft, Penkowski, Kaminska \& Drogoszewska, 2014). The process of crushing and powdering of bone fragments results in an increase in intensity of sharp resonance line at $g=2.008$ in comparison with the spectra of whole bone (Marino \& Becker, 1968). However, the mechanically induced signal is not stable and decreases with time elapsed since the sample preparation (Ciesielski et al., 2014). The radiation-induced signal is stable and has the form of singlet, which shows axial symmetry features $(g \perp=$ 2.003 and $g_{\|}=1.997$ ) both in X and Q-band EPR measurements (Strzelczak, Sadło, Danilczuk, Stachowicz, Callens, Vanhaelewyn, Goovaerts \& Michalik, 2007). The linear RIS dependence on the absorbed dose was observed up to $180 \mathrm{~Gy}$ (Krefft, Drogoszewska, Kaminska, Juniewicz, Wołąkiewicz, Jakacka \& Ciesielski, 2014).

\section{FINGER- OR TOENAILS EPR DOSIMETRY}

In times of emergency when large number of people can be potentially irradiated the process of collection and preparation of tooth enamel samples for EPR measurements would be very problematic. Therefore, scientists consider the option of using fingernails or toenails to estimate the absorbed doses, because nails parings might be gathered very quickly with minimal interference in patient's body. On the other hand it should be noted that in contrast to teeth, toe- and fingernails can provide information about the dose absorbed peripherally, i.e. apart from the main body axis and important organs.

Radicals, which are produced in nails under the influence of ionizing radiation, are probably localized in $\alpha$-keratin component (Trompier, Kornak, Calas, Romanyukha, Leblanc, Mitchell, Swartz \& Clairand 2007b) and stable for a relatively long time (days to weeks) (Wilcox et al., 2010). The basic radio-induced signal (often named RIS 2) is symmetric, isotropic singlet with $g=2.005$ (Trompier et al., 2014a). The comparative study has shown that the singlet with $g=$ 2.005 is present both in EPR spectra of feather keratin powder and human fingernails at room temperature (Strzelczak, Sterniczuk, Sadło, Kowalska \& Michalik, 2013). The rate of its decay depends on the sample storage condition. Specimens kept at $-4^{\circ} \mathrm{C}$ can be measured two weeks after the irradiation (Trompier et al., 2009), at $-20^{\circ} \mathrm{C}$ up to several weeks and those stored at liquid nitrogen temperature even months after the accident (Trompier et al., 2007b). The stability of RIS is also influenced by dampness, because the higher humidity speeds up the decay of this signal (Trompier et al., 2014a). Moreover, it should be remembered that humidity strongly affects the $\mathrm{Q}$ factor and the sensitivity of EPR measurements of non-frozen samples. It was shown that the storage of samples in vacuum for whole time between nails clipping and EPR measurements can ensure the stability of $g=2.005$ RIS signal for at least 7 days after radiation exposure (Sholom \& McKeever, 2016). It is worth mentioning that additional radiationinduced signals (labeled: RIS 1, RIS 3, RIS 4) can be observed for very high doses, but they are unimportant for emergency EPR dosimetry (Trompier et al., 2014a). The response of main radio-induced EPR signal to the dose is linear within the range $1-125$ Gy (Trompier et al., 2009).

Aside from RIS, EPR spectrum of nail sample contains the intrinsic background signal (BGS) and the mechanically induced signal (MIS), which unfortunately overlap with the main RIS line (Trompier et al., 2007b). The mechanically induced signal has four different components: the transient, symmetric doublet with $g=$ 2.007 (MIS 3), the broad anisotropic singlet with $g=$ 2.004 (MIS 2), MIS 1 with $g=2.003$ and MIS 4 ( $g=$ 2.008), which is detected using Q-band spectrometers (Trompier et al., 2014a; Wilcox et al., 2010). MIS 3 dominates after nails cutting, MIS 1 is important at lower microwave power (e.g. $3 \mathrm{~mW}$ ) in contrast to MIS 2 that contributes significantly only at higher power (Wilcox et al., 2010). The appearance of MIS is related to radicals generated during the process of nails cutting and the intensity of this signal depends on the size of the parings (Trompier et al., 2009). MIS originates mainly from the edges, so to minimize its influence on the measurements one should use large samples obtained with minimal number of cuts (Trompier et al., 2007b). Due to the fact that the process of giving the nails a soak reduces or even eliminates the MIS scientists consider rinsing the specimens in distilled water and drying afterwards to restore them to initial mass (Wilcox et al., 2010). As it turned out, the better solution is to moisten only the cut edges using wet paintbrush and thus selectively eliminate the MIS (Trompier et al., 2009). Radiation induced signal in nails is also strongly affected by water, so such treatment allows at least to maintain the RIS from the interior of the sample. Recent research aimed at checking whether the chemical treatment with different reagents can minimize the mechanically induced signal in nails showed that the use of dithiothreitol may significantly reduce the MIS and thus improve the linearity of the dose response curves (Noori, Mostajaboddavati \& Ziaie, 2018).

In contrast to MIS, the residual BGS (singlet with $g=$ 2.004) cannot be eradicated by humidification (Trompier et al., 2014a) and makes the measurements of doses $<5$ Gy difficult (Trompier et al., 2009). Until recently it 
appeared that the usefulness of nail dosimetry is restricted to the samples collected immediately after the radiation accident, because after each water treatment (e.g. hand washing) only BGS clearly remains in EPR spectrum.

The analysis of the residual signal after sample irradiation revealed the presence of additional, stable radiation-induced component (RIS 5) with $g=2.004$ and relatively weak intensity (Trompier et al., 2014a). It is interesting that the use of newly developed X-band rapid scan acquisition method allows to improve signal-tonoise ratio and lower a standard deviation of the signal amplitude values for repeated measurements of irradiated clipped fingernails in comparison with conventional continuous wave EPR (Elajaili, McPeak, Romanyukha, Aggarwal, Eaton \& Eaton, 2016). The RIS 5 resembles the intrinsic background signal and is still present after water treatment of nails. The only drawback is unusual dose response, because the RIS 5 decreases after reaching saturation. The measured intensity might be attributed to two different dose values, therefore there is a necessity of establishing whether the patient's dose was below or above the saturation dose, which can be done by additional irradiation of the sample (Trompier et al., 2014a). The protocol for EPR dosimetry, which utilizes stable radioinduced free radical component, has been already applied to assess the dose based on fingernail samples from victims of three radiological accidents that took place between 2008 and 2012 (Trompier, Queinnec, Bey, De Revel, Lataillade, Clairand, Benderitter \& Bottollier-Depois, 2014b). Another interesting example is the study, in which the nails were used to determine the dose received by the thumb of the worker irradiated accidentally by $130 \mathrm{kVp}$ X-rays. The dose estimation was performed independently using the same fingernail samples but two different spectrometers and approaches (transportable X-band and calibration curve versus stationary Q-band and dose saturation method based on RIS5 signal) (Romanyukha, Trompier, Reyes, Christensen, Iddins \& Sugarman, 2014b). Despite some discrepancy in the results $(14 \pm 3$ Gy and $19 \pm 6$ Gy, respectively), the authors emphasize that considering uncertainties there was a reasonable agreement between this two EPR dose assessments (Romanyukha et al., $2014 b$ ). In case of nails dosimetry which utilizes the singlet with $g=2.005$ the detection level is estimated at $5 \mathrm{~Gy}$, because for samples irradiated with lower doses the intensity of radiation-induced signal is similar to the intensity of the intrinsic signal (Strzelczak et al., 2013). It is worth mentioning that the intensities of native signals for samples collected from various people can differ even in 50\% (Strzelczak et al., 2013). In general, the studies have shown so far that the dose detection limit for EPR fingernails dosimetry is between 2 and 5 Gy and the estimated accuracy is 30\% (Trompier et al., 2007b).

\section{EPR DOSIMETRY OF HAIR}

Human hair is also under consideration for use in EPR dosimetry mainly due to the ease and noninvasiveness of sampling. Exposure to ionizing radiation results in the production of sulphur free radicals in $\alpha$-keratin, which is a major component of hair (Kudynski, Kudynska \& Buckmaster, 1994). It is worth mentioning that $\alpha$-keratin is a protein containing disulphide bridges between cysteine residues (Bruce Fraser \& Parry, 2012). Even though hair is regarded as an unstable dosimeter, the Xband EPR measurements of strongly dehydrated samples can be used for the assessment of absorbed doses shortly after irradiation (Płonka, 2009). However, the time after that the intensity of the RIS signal fall to its half-value depends on the colour of hair (Tepe Çam, Polat \& Seyhan, 2014). When samples are kept at room temperature radicals generated by gamma radiation are stable for several hours, but the storage at low temperature can prolong this period (Çolak \& Özbey, 2011). EPR studies showed the linearity of dose response in the 15-40 Gy range (Pembegul 1996). More recent measurements proved that the dose-response curves for hair samples are usually linear for doses 5-50 Gy and saturate close to 300 Gy (Tepe Çam et al., 2014). The $g$-factor values and peak-to-peak line widths of central resonance line for hair after irradiation were $g$ $=2.0031-2.0037$ and $\Delta B_{p p}=0.52-0.74 \mathrm{mT}$ respectively (Tepe Çam, et al., 2014). Differences in values were related to the color of hair shafts and the fact whether they were natural or dyed.

Unfortunately, radiation induced signal of human hair overlaps both with the background and the mechanically induced signals. A quite broad $\left(\Delta B_{p p}=0.47 \mathrm{mT}\right)$ and intense background singlet is very stable (Çolak \& Özbey, 2011). Its intensity depends on the hair color the smallest was observed for blonde hair, the largest for dark hair (Trivedi \& Greenstock, 1993). The signal originates from intrinsic radicals present in eumelanin, pheomelanin and erythromelanin in black, blonde and red hair, respectively (Kudynski, et al., 1994). It is worth recalling that melanin is a biological polymer and photoprotective pigment containing a population of semiquinone-like radicals (Herrling, Jung \& Fuchs, 2008). The $g$-factor values of background EPR lines are: 2.0037- 2.0041 for fair hair, 2.0040-2.0043 for dark hair and 2.0050-2.0052 for red hair (Pembegul 1996; Çolak \& Özbey, 2011). More accurate measurements indicated that in the case of red hair the native EPR signal is the superposition of two spectral shapes: the singlet from eumelanin and the triplet from pheomelanin. It is assumed that differences in $g$ values are related to the variation of the content of different melanin types in hair 
(Chikvaidze, Partskhaladze, Gogoladze, 2014). Additionally, high field $\mathrm{W}$ band $(93 \mathrm{GHz})$ EPR studies revealed background $\mathrm{Mn}^{2+}$ lines inevitably present in both hair and nail samples (Tipikin, Swarts, Sidabras, Trompier \& Swartz, 2016). Another signal overlapping the RIS line comes from sulfur radicals generated in the $\alpha$-keratin structure during the hair cutting process (Çolak \& Özbey, 2011).

Hair was initially thought to be promising dosimetric material in case of accidental irradiation (Dalgarno \& Mcclymont, 1989). Nowadays, it is assumed that it is unlikely that hair could be suitable at the dose levels $\leq$ $2 \mathrm{~Gy}$ needed for triage due to the strong background signal from melanin (Tepe Çam, et al., 2014).

\section{Q-BAND SPECTROMETERS IN EPR DOSIMETRY}

Due to the fact that classical X-band $(9.4 \mathrm{GHz})$ spectrometers require large $(>100 \mathrm{mg})$ tooth enamel samples and allow to obtain the spectra in which the RIS is separated from the native background signal only for doses greater than $0.5 \mathrm{~Gy}$, Q-band machines working at $34 \mathrm{GHz}$ are more and more often used for dosimetric applications (Romanyukha et al., 2007; Pass et al., 2009). High-frequency spectrometers have better spectral resolution and thus are capable of distinguishing the radiation induced signal from non-radiation components without the implementation of spectral deconvolution (Romanyukha et al., 2014a). It is worth noting that the application of Q-band increases the sensitivity of measurements by a factor of 20 (Pass et al., 2009). Consequently there is a possibility of reducing the sample size. Measurements of doses smaller than 0.5 Gy can be accurately carried out using tooth enamel specimens of $2 \mathrm{mg}$ (Romanyukha et al., 2007). The studies have shown that the optimal quantity of tooth enamel for Q-band dose determination adds up to $4 \mathrm{mg}$, which is less than $1 \%$ of the enamel present in one molar (Romanyukha et al., 2007). Such a small sample has for instance dimensions of $1 \times 1 \times 3 \mathrm{~mm}$ and can be easily obtain in vivo by enamel-slab biopsy (Pass et al., 2009). There is no need for extracting a whole tooth. It is interesting to note that more than $20 \mathrm{mg}$ of healthy enamel is typically removed during a visit to a dentist when the tooth is drilled (Romanyukha et al., 2014a). The biopsy of a small chip of 2-10 $\mathrm{mg}$ of tooth enamel for a dosimetric reason is therefore minimallyinvasive and might be quickly performed on radiation accident victim. The measurement time for the Q-band EPR spectrometer is less than $15 \mathrm{~min}$ (Romanyukha et al., 2014a).

The advantages of Q-band (higher sensitivity and better spectral resolution in comparison with X-band) are visible both for calcified tissues (bones and enamel) and for nails (Trompier et al., 2014a). Unfortunately, this technique generates also some problems, mainly with exactly positioning of the small, irregular sample in the resonator. Due to the high sensitivity of Q-band spectrometer small changes in the specimen location and the redistribution of its grains in the tube are responsible for the lower signal reproducibility compared with Xband (Romanyukha et al., 2007). The amplitude of RIS recorded for a small tooth enamel chip can differ even more than a factor of 2 depending on the sample orientation in the external magnetic field (De et al., 2013). This anisotropy has a significant impact on the precision of dose measurement. Recent study has shown that the approach, which utilizes an average of the radiation responses (amplitudes) measured at different sample orientations, provides the most accurate results (De et al., 2013). As mentioned before, stationary Qband spectrometer has been already used for EPR fingernails dosimetry in case of a worker whose thumb had been accidentally irradiated. In this study the uncertainty was $6 \mathrm{~Gy}$, which accounted for over $31 \%$ of the calculated dose (Romanyukha et al., 2014b). The Qband EPR measurements of irradiated samples of powdered dentine and bone have indicated that potentially achievable lower limit of detection (LLD) is 3-5 Gy for dentine and 5-10 Gy for bone (De et al., 2013). It is worth mentioning that microwaves of higher frequency enter into the sample to a smaller depth because of increased dielectric losses (Williams et al., 2014).

\section{L-BAND SPECTROMETERS IN EPR DOSIMETRY}

L-band spectrometers work at lower microwave frequency of $1-1.2 \mathrm{GHz}$, which is safe according to FDA-approved standards (Flood, Bhattacharyya, Nicolalde \& Swartz, 2007) and less affected by the water content in a sample (Swartz, Iwasaki, Walczak, Demidenko, Salikov, Lesniewski, Starewicz, Schauer \& Romanyukha, 2005). These systems enable to perform in vivo EPR measurements of whole tooth or even several teeth in the patient's mouth in non-invasive way. There is no need for enamel biopsy or removing the teeth, that minimizes stress related to the process of tissue sampling and predestines this method to triage applications (Williams et al., 2014). Initially, large clinical devices equipped with an electromagnet or a permanent magnet were used for in vivo EPR dosimetry (Swartz et al., 2005; Iwasaki, Grinberg, Walczak \& Swartz, 2005; Williams, Dong, Flood, Grinberg, Kmiec, Lesniewski, Matthews, Nicolalde, Raynolds, Salikhov \& Swartz, 2011). The patient was lying in supine position within large $50 \mathrm{~cm}$ gap of the magnet. Nowadays, scientists aim at developing the systems, which can be easily transported to the place where accident happened and used for screening of the large number of potential 
victims. Such devices have been already constructed. One can cite the examples of the rotated flat magnet with a diameter of $26 \mathrm{~cm}$ and weight (with power supply) about $80 \mathrm{~kg}$ (Swartz et al., 2005) or the $30 \mathrm{~kg}$ permanent dipole magnet with a $17 \mathrm{~cm}$ gap (Williams et al., 2014). First mentioned system ensures the sufficient field homogeneity directly in the oral cavity when patient's head rests on the surface of the encompassing magnet (Swartz et al., 2005). In case of the second one, the head is positioned and immobilized in the magnetic field using an instrument to rest the teeth and hold the lip (Williams et al., 2014). The value of magnetic field induction of permanent magnets in L-band spectrometers designed for in vivo dosimetry is about 41 mT (Williams et al., 2014; Flood et al., 2007; Williams et al., 2011). The field sweep (in the range of $4 \mathrm{mT}$ ) and modulation are done thanks to additional small electromagnets (Williams et al., 2011).

In vivo EPR measurements in the patient's mouth require special sensing loops installed in the resonator and placed on the tooth. These loops can be made of high-purity silver wire and covered by a thin plastic hygienic barrier (Williams et al., 2014). Some of them are designed for molars, another for incisors (Bhat, 2005). The incisors can be fitted between two loops, which provides comparatively homogeneous $B_{l}$ field within these teeth. In contrast, the top of irregular molars might be surrounded by larger single loop (Swartz et al., 2005). The resonator probes simultaneously 1-4 teeth (Iwasaki et al., 2005). The optimal construction of resonator and loops presents the technical challenge because of different size and irregular shape of the teeth (Swartz et al., 2005). Furthermore, neighboring tissues that non-resonantly attenuate the microwave frequencies are responsible for the decrease in Q-factor (Iwasaki et al., 2005; Demidenko, Williams, Sucheta, Dong \& Swartz, 2007). Therefore, it is important to situate the tongue far from the resonator and avoid the motion during the measurements (Iwasaki et al., 2005).

In vivo EPR measurements for dose estimation and screening have been already performed using unharmed upper incisors in healthy volunteers and patients subjected to total body irradiation before bone marrow transplant (Williams et al., 2014). In such a case the dose estimation is usually done based on calibration curve, which is established by measuring the radiation response of a large number of teeth (Swartz et al., 2005). The additive dose method cannot be used in vivo, but there is a possibility of irradiating the teeth arranged in oral cavity model. The radiation induced EPR signal for intact incisors and molars increases linearly with radiation dose and the existence of amalgam fillings does not affect the accuracy of measurements (Iwasaki et al., 2005). The exactitude of EPR dose estimates can be assessed by means of the standard error of prediction (SEP). For in vivo dosimetry carried out using a clinical
L-band spectrometer the SEP values were approximately evaluated at $1.5 \mathrm{~Gy}$ for molar teeth and between 2.0 and 2.5 Gy for more irregularly shaped canine teeth (Williams, Dong, Kmiec, Burke, Demidenko, Gladstone, Nicolalde, Sucheta, Lesniewski \& Swartz, 2010). The precision of measurements will improve along with the development of magnets, resonators and dose calculating algorithms. There is a chance that $\mathrm{S}$ band spectrometers operating at $2.4 \mathrm{GHz}$ will have application to in vivo EPR dosimetry. These systems allow to enhance the signal-to-noise ratio about 2.5-fold and better quantify the doses < 1 Gy (Williams et al., 2014). In vivo spectrometers can potentially measure the RIS in an intact fingernail (a 10 fold larger sample than the nail paring and the absence of MIS), but the sensitivity of current systems is not good enough for such an application (Wilcox et al., 2010). However, the situation may change in the near future, because surface dielectric resonator with two-element coupling loop has been developed recently. Such a device has the capability to perform in vivo EPR spectroscopy of human fingernails with higher sensitivity at X-band frequencies (Petryakov, Schreiber, Kmiec, Williams, Swartz, 2016). In an emergency situation there is a need for rapid screening, hence the aspiration to refinements, miniaturization of the systems and automation of measurement procedures (Williams et al., 2011). It is worth noting that using in vivo EPR dosimetry method one can assess the absorbed dose immediately after the measurements and whole procedure takes 5 to $10 \mathrm{~min}$ per individual (Flood et al., 2007).

\section{EPR DOSIMETRY AFTER THE RADIATION ACCIDENTS}

In the situation of a large scale radiation accident EPR dosimetry might be used to classify casualties according to the degree of exposure to provide medical care in the right order (Trompier, Fattibene, Woda, Bassinet, Bortolin, De Angelis, Della Monaca, Viscomi \& Wieser, 2012). On the other hand EPR measurements are often carried out to assess the health risk in people living in contaminated area for a long time.

The EPR tooth enamel dosimetry has been already used to assess the cumulative radiation dose in school children dwelling 30- $60 \mathrm{~km}$ from Chernobyl reactor (Gualtieri et al., 2001), people from Hiroshima and Nagasaki (Williams et al., 2014), population of settlements situated in the vicinity of Semipalatinsk Nuclear Test Site (SNTS) region in Kazakhstan (Zhumadilov et al., 2013; Zhumadilov et al., 2011), workers of industrial reactors in the Mayak Production Association (MPA), people living in Ozyorsk (Wieser et al., 2014) and by the side of contaminated Techa river in Russia (Shishkina, Degteva, Tolstykh, Volchkova 
Ivanov, Wieser, Della Monaca \& Fattibene, 2011). The last instance was particularly interesting, because scientists wanted to check whether tooth enamel could be useful for EPR dosimetry in case of combined (external and internal) radiation exposure. As a result of several accidents, which took place in MPA nuclear weapons facilities, radioactive aerosols and gaseous fission products were released to atmosphere (Wieser et al., 2014). Gamma emitting radionuclides deposited in the Techa River banks and bottom sediments were responsible for external exposure, in contrast to betaemitting ${ }^{90} \mathrm{Sr}$, which constituted the source of an internal irradiation as a result of drinking contaminated water (Shishkina et al., 2011). The studies showed that doses determined based on teeth which were under mineralization during the maximal intake of ${ }^{90} \mathrm{Sr}$ cannot be extrapolated to another parts of the body, because enamel at this stage of development incorporates the isotope into calcium hydroxyapatite crystals resulting in high local beta exposure (Shishkina et al., 2011). Therefore, another EPR dosimetric study of the inhabitants of Techa river region encompassed only teeth donors who met two criteria: living within $70 \mathrm{~km}$ from the release site in 1950 - 1952 (maximization of the external dose) and the beginning of their teeth mineralization at least 6 years before the start of massive radioisotope intake (reduction of the ${ }^{90} \mathrm{Sr}$ dose contribution) (Degteva, Shagina, Shishkina, Vozilova, Volchkova, Vorobiova, Wieser, Fattibene, Della Monaca, Ainsbury, Moquet, Anspaugh, Napier, 2015). It is worth mentioning that during 20 years the results of EPR measurements of 302 teeth donated by 173 permanent residents of the Techa riverside were analyzed in order to reconstruct the doses from several sources of exposure (Shishkina, Volchkova, Timofeev, Fattibene, Wieser, Ivanov, Krivoschapov, Zalyapin, Della Monaca, De Coste, Degteva, Anspaugh, 2016).

In the context of severe accidents it is also necessary to mention the measurements performed after Fukushima Daiichi nuclear power plant disaster due to the earthquake and tsunami on 11 March 2011 in Japan. A portable L-band EPR spectrometer was used for the estimation of the absorbed dose within the oral cavity of thirty four residents in Fukushima prefecture. The study confirmed that the magnitude of the EPR signals from inhabitants of Fukushima did not differ from that observed in people who never had a potential overexposure to radiation (Miyake, Nakai, Yamaguchi, Hirata, Kunugita, Williams \& Swartz, 2016).

Except for such cases EPR tooth enamel dosimetry is an approved and validated method for individual retrospective dose assessment (Williams et al., 2014). In practice also bone samples are used to determine the unknown absorbed doses, especially in patients undergoing surgical operation after severe radiation events. EPR dosimetric measurements of rib samples were carried out after real and suspected overexposures during radiotherapy treatments in Poland. The famous accident took place in the year 2001 in the Bialystok Oncology Center, where five breast cancer patients received a high dose of $8 \mathrm{MeV}$ electrons from Neptun linear accelerator (Trompier et al., 2007a). Suspected overexposure of patient with Hodgkin's disease undergoing radiotherapy with $9 \mathrm{MV}$ photons occurred in Regional Cancer Center in Gdynia in 1999, but in this case the necrosis of bone sample influenced the EPR measurements (Trompier et al., 2007a). EPR dosimetry was also used for dose reconstruction in four patients treated in France after the severe radiation accident, which happened in 2006 in Senegal and in Ivory Coast due to failure of gammagraphy equipment containing an

${ }^{192}$ Ir radioactive source (Clairand et al., 2008). In this case measurements were based on two bone samples taken from the patient's arm and enamel specimens collected from the other three victims. Another example of a patient for whom the physical dose reconstruction was carried out in France is the victim of radiological accident that occurred in Georgia in December 2001 (Clairand, Trompier, Bottollier-Depois \& Gourmelon, 2006). Three bone samples (collected from two ribs and a vertebra) were used for the estimation of the dose distribution within the body that had been exposed to two very high activity ${ }^{90} \mathrm{Sr}$ sources.

In addition to radiation accidents the problem of the assessment of the absorbed dose may concern astronauts exposed to cosmic ray. Acute radiation syndrome can develop during long space missions beyond low Earth orbit due to the impact of charged galactic cosmic radiation: protons, alpha particles and atomic nuclei moving at relativistic speeds and energies (Chancellor, Scott \& Sutton, 2014). Therefore there is a need for a stable dosimeter that ensures a continuous record of the cumulative dose in space. The prospect of using EPR dosimetry seems promising, but it is necessary to verify the response of tooth enamel to high-LET radiation (Haskell, Hayes, Kenner, Sholom \& Chumak, 1997). The first experiments utilizing heavy ions have shown that it would be possible to detect radicals generated in teeth during a space flight (Yamaguchi et al., 2016). Research in this field will certainly be continued in the nearest future.

\section{CONCLUSIONS}

The usefulness of the EPR dosimetry for the retrospective assessment of absorbed dose has been proven for both large-scale radiation accidents and cases of individual overexposures. Tooth enamel and bones are the most stable and reliable cumulative dosimeters. Hair and nails are easy to collect, but their use requires dealing with strong background and mechanically 
induced signals. Table 1 summarizes the values of $g$ factors for particular types of signals recorded for

different materials currently used in EPR dosimetry.

Table 1. $g$ - factor values of radiation-induced signals (RIS), background signals (BGS) and mechanically induced signals (MIS) for various dosimetric materials.

\begin{tabular}{|c|c|c|c|c|}
\hline Type of dosimeter & RIS & BGS & MIS & References \\
\hline tooth enamel & $\begin{array}{l}g_{\perp}=2.0019-2.0025 \\
g_{\|}=1.9973\end{array}$ & $g=2.0045$ & $g=2.0032$ & $\begin{array}{l}\text { Romanyukha et al., } \\
\text { 2007; } \\
\text { El-Faramawy, 2005; } \\
\text { Aragno et al., 2001; }\end{array}$ \\
\hline bones & $\begin{array}{l}g_{\perp}=2.003 \\
g_{\|}=1.997\end{array}$ & $g=2.008$ & $g=2.008$ & $\begin{array}{l}\text { Strzelczak, et al., 2007; } \\
\text { Marino \& Becker, } \\
\text { 1968; }\end{array}$ \\
\hline finger- and toenails & $\begin{array}{l}g=2.005 \text { (RIS2) } \\
g=2.004 \text { (RIS5) }\end{array}$ & $g=2.004$ & $\begin{array}{l}g=2.003(\mathrm{MIS} 1) \\
g=2.004(\mathrm{MIS} 2) \\
g=2.007(\mathrm{MIS} 3) \\
g=2.008(\mathrm{MIS} 4)\end{array}$ & $\begin{array}{l}\text { Trompier et al., 2014a; } \\
\text { Wilcox et al., 2010; }\end{array}$ \\
\hline hair & $g=2.0031-2.0037$ & $\begin{array}{l}2.0037-2.0041 \\
\text { (fair hair) } \\
2.0040-2.0043 \\
\text { (dark hair) } \\
\text { 2.0050-2.0052 } \\
\text { (red hair) }\end{array}$ & $g \approx 2.0033$ & $\begin{array}{l}\text { Tepe Çam, et al., 2014; } \\
\text { Çolak \& Özbey, } 2011\end{array}$ \\
\hline
\end{tabular}

\section{REFERENCES}

Aragno D., Fattibene P. \& Onori S. (2001). Mechanically induced EPR signals in tooth enamel. Appl. Radiat. Isot., 55, $375-382$.

Bhat M. (2005). EPR tooth dosimetry as a tool for validation of retrospective doses: an end-user perspective. Appl. Radiat. Isot., 62, 155-161.

Brady J. M., Aarestad N. O. \& Swartz H.M. (1968). In vivo dosimetry by electron spin resonance spectroscopy. Health Phys., 15, 43-47.

Bruce Fraser R. D. \& Parry D.A. (2012). The role of disulfide bond formation in the structural transition observed in the intermediate filaments of developing hair. J. Struct. Biol., 180, 117-124.

Chancellor J. C., Scott G. B. I. \& Sutton J. P. (2014). Space Radiation: The Number One Risk to Astronaut Health beyond Low Earth Orbit. Life, 4, 491-510.

Chikvaidze E. N., Partskhaladze T. M. \& Gogoladze T. V. (2014). Electron spin resonance (ESR/EPR) of free radicals observed in human red hair: a new, simple empirical method of determination of pheomelanin/eumelanin ratio in hair. Magn. Reson. Chem. 52, 377-382.

Chumak V. V., Sholom S. V., Bakhanova E. V., Pasalskaya L. F. \& Musijachenko A. V. (2005). High precision EPR dosimetry as a reference tool for validation of other techniques. Appl. Radiat. Isot., 62, 141-146.

Ciesielski B., Krefft K., Penkowski M., Kaminska J. \& Drogoszewska B. (2014). Effects of water treatment and sample granularity on radiation sensitivity and stability of EPR signals in X-ray irradiated bone samples. Radiat. Prot. Dosim., 159, 141-148.

Clairand I., Huet C., Trompier F. \& Bottollier-Depois J.F. (2008). Physical dosimetric reconstruction of a radiological accident due to gammagraphy equipment that occurred in Dakar and Abidjan in summer 2006. Radiat. Meas., 43, 698703.

Clairand I., Trompier F., Bottollier-Depois J. F. \& Gourmelon P. (2006). Ex vivo ESR measurements associated with monte carlo calculations for accident dosimetry: application to the 2001 Georgian accident. Radiat. Prot. Dosim., 119, 500-505.

Çolak Ş. \& Özbey T. (2011). An ESR study on biological dosimeters: Human hair. Radiat. Meas., 46, 465-472.

Dalgarno B. G. \& Mcclymont J. D. (1989). Evaluation of ESR as a radiation accident dosimetry technique. Int. J. Rad. Appl. Instrum. A, 40, 1013-1020.

De T., Romanyukha A., Trompier F., Pass B. \& Misra P. (2013). Feasibility of Q-Band EPR Dosimetry in Biopsy Samples of Dental Enamel, Dentine and Bone. Appl. Magn. Reson., 44, 375-387.

Degteva M. O., Shagina N. B., Shishkina E. A., Vozilova A. V., Volchkova A. Y., Vorobiova M. I., Wieser A., Fattibene P., Della Monaca S., Ainsbury E., Moquet J., Anspaugh L. R. \& Napier B. A. (2015). Analysis of EPR and FISH studies of radiation doses in persons who lived in the upper reaches of the Techa River. Radiat. Environ. Biophys., 54, 433-444.

Demidenko E., Williams B. B., Sucheta A., Dong R. \& Swartz H. M. (2007). Radiation dose reconstruction from L-band in vivo EPR spectroscopy of intact teeth: Comparison of methods. Radiat. Meas., 42, 1089-1093.

Elajaili H., McPeak J., Romanyukha A., Aggarwal P., Eaton S. S. \& Eaton G. R. (2016). Comparison of continuous wave and rapid scan X-band electron paramagnetic resonance of irradiated clipped fingernails. Radiat. Prot. Dosim., 172, 133-138. 
El-Faramawy N. A. (2005). Estimation of radiation levels by EPR measurement of tooth enamel in Indian populations. Appl. Radiat. Isot., 62, 207-211.

Fattibene P. \& Callens F. (2010). EPR dosimetry with tooth enamel: A review. Appl. Radiat. Isot., 68, 2033-2116.

Fattibene P., Trompier F., Wieser A., Brai M., Ciesielski B., De Angelis C., Della Monaca S., Garcia T., Gustafsson H., Hole E. O., Juniewicz M., Krefft K., Longo A., Leveque P., Lund E., Marrale M., Michalec B., Mierzwińska G., Rao J. L., Romanyukha A. A. \& Tuner H. (2014). EPR dosimetry intercomparison using smart phone touch screen glass. Radiat. Environ. Biophys., 53, 311-320.

Fattibene P., Wieser A., Adolfsson E., Benevides L. A., Brai M., Callens F., Chumak V., Ciesielski B., Della Monaca S., Emerich K., Gustafsson H., Hirai Y., Hoshi M., Israelsson A., Ivannikov A., Ivanov D., Kaminska J., Ke W., Lund E., Marrale M., Martens L., Miyazawa C., Nakamura N., Panzer W., Pivovarov S., Reyes R.A., Rodzi M., Romanyukha A. A., Rukhin A., Sholom S., Skvortsov V., Stepanenko V., Tarpan M.A., Thierens H., Toyoda S., Trompier F., Verdi E. \& Zhumadilov K. (2011). The 4th international comparison on EPR dosimetry with tooth enamel Part 1: Report on the results. Radiat. Meas., 46, 765-771.

Flood A. B., Bhattacharyya S., Nicolalde R. J. \& Swartz H. M. (2007). Implementing EPR dosimetry for life-threatening incidents: Factors beyond technical performance. Radiat. Meas., 42, 1099-1109.

Gualtieri G., Colacicchi S., Sgattoni R. \& Giannoni M. (2001). The Chernobyl accident: EPR dosimetry on dental enamel of children. Appl. Radiat. Isot., 55, 71-79.

Haskell E. H., Hayes R. B., Kenner G. H., Sholom S. V. \& Chumak V. I. (1997). Electron Paramagnetic Resonance Techniques and Space Biodosimetry. Radiat. Res., 148, S51S59.

Herrling T., Jung K. \& Fuchs J. (2008). The role of melanin as protector against free radicals in skin and its role as free radical indicator in hair. Spectrochim. Acta A, 69, 14291435.

Iwasaki A., Grinberg O., Walczak T. \& Swartz H. M. (2005). In vivo measurements of EPR signals in whole human teeth. Appl. Radiat. Isot., 62, 187-190.

Kip A. F., Kittel C., Levy R. A \& Portis A. M. (1953). Electronic structure of $\mathrm{F}$ centers: hyperfine interactions in electron spin resonance. Phys. Rev., 91, 1066-1071.

Krefft K., Drogoszewska B., Kaminska J., Juniewicz M., Wołąkiewicz G., Jakacka I. \& Ciesielski B. (2014). Application of EPR dosimetry in bone for ex vivo measurements of doses in radiotherapy patients. Radiat. Prot. Dosim., 162, 38-42.

Kudynski R., Kudynska J. \& Buckmaster H. A. (1994). The decay constant for irradiated human hair using EPR spectroscopy. Appl. Radiat. Isot., 45, 645-650.

Marino A. A. \& Becker R.O. (1968). Mechanically Induced Free Radicals in Bone, Nature, 218, 466-467.

Miyake M., Nakai Y., Yamaguchi I., Hirata H., Kunugita N., Williams B. B. \& Swartz H. M. (2016). In-vivo radiation dosimetry using portable L-band EPR: on-site measurement of volunteers in Fukushima prefecture, Japan. Radiat. Prot. Dosim., 172, 248-253.

Murahashi M., Toyoda S., Hoshi M., Ohtaki M., Endo S., Tanaka K. \& Yamada Y. (2017). The sensitivity variation of the radiation induced signal in deciduous teeth to be used in ESR tooth enamel dosimetry. Radiat. Meas., 106, 450-454.

Noori A., Mostajaboddavati M. \& Ziaie F. (2018). Retrospective dosimetry using fingernail electron paramagnetic resonance response, Nucl. Eng. Technol., 50, 526-530.

Onori S., Aragno D., Fattibene P., Petetti E. \& Pressello M.C. (2000). ISS protocol for EPR tooth dosimetry. Radiat. Meas., 32, 787-792.

Pass B., De T., Romanyukha A. \& Misra P. (2009). Human Radiation Dosimetry Using EPR in Dental Enamel and The Tides of Fear. Oral. Surg. Oral. Med. Oral. Patho., 107, 2930.

Pembegul, S., "Electron spin resonance study of gammairradiated hair and nails", MSc Thesis, Hacettepe University, Ankara 1996.

Petryakov S. V., Schreiber W., Kmiec M. M., Williams B. B. \& Swartz H. M. (2016). Surface dielectric resonators for Xband EPR spectroscopy. Radiat. Prot. Dosim., 172, 127-132.

Płonka P. M. (2009). Electron paramagnetic resonance as a unique tool for skin and hair research. Exp. Dermatol., 18, 472-484.

Rajewsky B. \& Redhardt A. (1962). Time-dependence of the Radical State in an X-irradiated Keratin. Nature, 195, 492494.

Romanyukha A., Mitchell C. A., Schauer D. A., Romanyukha L. \& Swartz H. M. (2007). Q-Band EPR Biodosimetry in Tooth Enamel Microsamples: Feasibility Test and Comparison With X-Band. Health Phys., 93, 631-635.

Romanyukha A., Trompier F. \& Reyes R. A. (2014a). Q-band electron paramagnetic resonance dosimetry in tooth enamel: biopsy procedure and determination of dose detection limit. Radiat. Environ. Biophys., 53, 305-310.

Romanyukha A., Trompier F., Reyes R. A., Christensen D. M, Iddins C.J. \& Sugarman, S.L. (2014b). Electron paramagnetic resonance radiation dose assessment in fingernails of the victim exposed to high dose as result of an accident. Radiat. Environ. Biophys., 53, 755-762.

Shishkina E. A., Degteva M. O., Tolstykh E. I., Volchkova A., Ivanov D. V., Wieser A., Della Monaca S. \& Fattibene P. (2011). Extra-high doses detected in the enamel of human teeth in the Techa riverside region. Radiat. Meas., 46, 760764.

Shishkina E. A., Volchkova A.Y, Timofeev Y. S., Fattibene P., Wieser A., Ivanov D. V., Krivoschapov V. A., Zalyapin V. I., Della Monaca S., De Coste V., Degteva M. O. \& Anspaugh L. R. (2016). External dose reconstruction in tooth enamel of Techa riverside residents. Radiat. Environ. Biophys., 55, 477-499.

Sholom S. V., Haskell E. H., Hayes R. B., Chumak V. V. \& Kenner G. H. (1998). Influence of crushing and additive irradiation procedures on EPR dosimetry of tooth enamel. Radiat. Meas., 29, 105-111.

Sholom S. \& McKeever S.W.S. (2016). Emergency EPR dosimetry technique using vacuum-stored dry nails. Radiat. Meas., 88, 41-47.

Sholom S. \& McKeever S.W.S. (2017). Developments for emergency dosimetry using components of mobile phones. Radiat. Meas., 106, 416-422.

Sleptchonok O. F., Nagy V. \& Desrosiers M. F. (2000). Advancements in accuracy of the alanine dosimetry system. Part 1. The effects of environmental humidity. 
Radiat. Phys. Chem., 57, 115-133.

Strzelczak G., Sadło J., Danilczuk M., Stachowicz W., Callens F., Vanhaelewyn G., Goovaerts E. \& Michalik J. (2007). Multifrequency electron paramagnetic resonance study on deproteinized human bone. Spectrochim. Acta A Mol. Biomol. Spectrosc., 67, 1206-1209.

Strzelczak G., Sterniczuk M., Sadło J., Kowalska M. \& Michalik J. (2013). EPR study of $\gamma$-irradiated feather keratin and human fingernails concerning retrospective dose assessment. Nukleonika, 58, 505-509.

Swartz H. M., Iwasaki A., Walczak T., Demidenko E., Salikov I., Lesniewski P., Starewicz P., Schauer D. \& Romanyukha A. (2005). Measurements of clinically significant doses of ionizing radiation using non-invasive in vivo EPR spectroscopy of teeth in situ. Appl. Radiat. Isot., 62, 293299.

Tepe Çam S., Polat M. \& Seyhan N. (2014). The use of human hair as biodosimeter. Appl. Radiat. Isot., 94, 272-281.

Tipikin D. S., Swarts S. G., Sidabras J. W., Trompier F. \& Swartz H.M. (2016). Possible nature of the radiationinduced signal in nails: high-field EPR, confirming chemical synthesis and quantum chemical calculations. Radiat. Prot. Dosim., 172, 112-120.

Trivedi A. \& Greenstock C. L. (1993). Use of sugars and hair for ESR emergency dosimetry. Appl. Radiat. Isot., 44, 8590.

Trompier F., Della Monaca S., Fattibene P. \& Clairand I. (2011). EPR dosimetry of glass substrate of mobile phone LCDs. Radiat . Meas., 46, 827-831.

Trompier F., Fattibene P., Tikunov D., Bartolotta A., Carosi A., \& Doca M. C. (2004). EPR dosimetry in a mixed neutron and gamma radiation field. Radiat. Prot. Dosim., 110, 437-442.

Trompier F., Fattibene P., Woda C., Bassinet C., Bortolin E., De Angelis C., Della Monaca S., Viscomi D. \& Wieser A. (2012). Retrospective dose assessment in a radiation mass casualty by EPR and OSL in mobile phones. [In:] The proceedings of the 13th IRPA International Congress., Glasgow, UK, pp.13-18.

Trompier F., Kornak L., Calas C., Romanyukha A., Leblanc B., Mitchell C. A., Swartz H. M. \& Clairand I. (2007b). Protocol for emergency EPR dosimetry in fingernails. Radiat. Meas., 42, 1085-1088

Trompier F., Queinnec F., Bey E., De Revel T., Lataillade J. J., Clairand I., Benderitter M. \& Bottollier-Depois J. F. (2014b). EPR retrospective dosimetry with fingernails: report on first application cases. Health Phys.,106, 798805.

Trompier F., Romanyukha A., Kornak L., Calas C., LeBlanc B., Mitchell C., Swartz H. \& Clairand I. (2009). Electron paramagnetic resonance radiation dosimetry in fingernails. Radiat. Meas., 44, 6-10.

Trompier F., Romanyukha A., Reyes R., Vezin H., Queinnec F. \& Gourier D. (2014a). State of the art in nail dosimetry: free radicals identification and reaction mechanisms. Radiat. Environ. Biophys., 53, 291-303.

Trompier F., Sadlo J., Michalik J., Stachowicz W., Mazal A., Clairand I., Rostkowska J., Bulski W., Kulakowski A., Sluszniak J., Gozdz S. \& Wojcik A. (2007a). EPR dosimetry for actual and suspected overexposures during radiotherapy treatments in Poland. Radiat. Meas., 42, 1025-1028.
Trompier F., Tikunov D. D., Ivannikov A. \& Clairand I. (2006). ESR investigation of joint use of dentin and tooth enamel to estimate photon and neutron dose components of a mixed field. Radiat. Prot. Dosim., 120, 191-196.

Volchkova A., Shishkina E. A., Ivanov D., Timofeev Y., Fattibene P., Della Monaca S., Wieser A. \& Degteva M. O. (2011). Harmonization of dosimetric information obtained by different EPR methods: Experience of the Techa river study. Radiat. Meas., 46, 801-807.

Wieser A., Vasilenko E., Aladova E., Fattibene P., Semiochkina N. \& Smetanin M. (2014). Electron paramagnetic resonance measurements of absorbed dose in teeth from citizens of Ozyorsk. Radiat. Environ. Biophys., 53, 321-333.

Wilcox D. E., He X., Gui J., Ruuge A. E., Li H., Williams B. B. \& Swartz H. M. (2010). Dosimetry Based on EPR Spectral Analysis of Fingernail Clippings. Health Phys., 98, 309-317.

Williams B. B., Dong R., Flood A. B., Grinberg O., Kmiec M., Lesniewski P.N., Matthews T.P., Nicolalde R. J., Raynolds T., Salikhov I. K. \& Swartz H. M. (2011). A Deployable in vivo EPR tooth dosimeter for triage after a radiation event involving large populations. Radiat. Meas., 46, 772-777.

Williams B. B., Dong R., Kmiec M., Burke G., Demidenko E., Gladstone D., Nicolalde R. J., Sucheta A., Lesniewski P. \& Swartz H. M. (2010). Development of in vivo tooth EPR for individual radiation dose estimation and screening. Health Phys., 98, 327-338.

Williams B. B., Flood A. B., Salikhov I., Kobayashi K., Dong R., Rychert K., Du G., Schreiber W. \& Swartz H. M. (2014). In vivo EPR tooth dosimetry for triage after a radiation event involving large populations. Radiat. Environ. Biophys., 53, 335-346.

Yamaguchi I., Sato H., Kawamura H., Hamano T., Yoshii H., Suda M., Miyake M. \& Kunugita N. (2016). L band EPR tooth dosimetry for heavy ion irradiation. Radiat. Prot. Dosim., 172, 81-86.

Zhumadilov K., Ivannikov A., Stepanenko V., Zharlyganova D., Toyoda S., Zhumadilov Z. \& Hoshi M. (2013). ESR dosimetry study of population in the vicinity of the Semipalatinsk Nuclear Test Site., J. Radiat. Res., 54, 775779.

Zhumadilov K., Ivannikov A., Zharlyganova D., Zhumadilov Z., Stepanenko V., Abralina S., Sadvokasova L., Zhumadilova A., Toyoda S., Endo S., Okamoto T. \& Hoshi M. (2011). ESR dosimetry study for the residents of Kazakhstan exposed to radioactive fallout on 24, August 1956. Radiat. Meas., 46, 793-796. 